\title{
Operations Scheduling of Sugarcane Production Using Classical Gert Method (Part Ii: Preserve Operations, Harvesting and Ratooning)
}

\author{
Nasim Monjezi (Corresponding author) \\ Department of Agricultural Machinery, Faculty of Agriculture \\ Shahid Chamran University, PO box 6166616453, Ahvaz, Iran \\ Tel: 0098-930-201-6425Ｅ-mail: N-monjezi@phdstu.scu.ac.ir
}

Mohammad Javad Sheikhdavoodi

Department of Agricultural Machinery, Faculty of Agriculture

Shahid Chamran University, Ahvaz, Iran

Tel: 0098-916-311-6165Ｅ-mail: javad1950@gmail.com

\author{
Hasan Zakidizaji \\ Department of Agricultural Machinery, Faculty of Agriculture \\ Shahid Chamran University, Ahvaz, Iran \\ Tel: 0098-912-479-3407Ｅ-mail: hzakid@scu.ac.ir
}

\begin{abstract}
Afshin Marzban
Department of Agricultural Machinery

Ramin Agriculture and Natural Resources University, Mollasani, Ahvaz, Iran
\end{abstract}

Tel: 0098-916-618-2246Ｅ-mail: afshinmarzban@hotmail.com

Mahmood Shomeili

Manager of Agronomy Department in Iranian Sugarcane Research and Training Institute

Tel: 0098-916-853-3386Ｅ-mail: eshomeli@gmail.com 
Received: April 14, 2015 Accepted: April 30, 2015

doi:10.5296/jas.v3i2.7421

URL: http://dx.doi.org/10.5296/jas.v3i2.7421

\begin{abstract}
Graphical Evaluation and Review Technique (GERT) is a systems analysis technique for project management. GERT provides a visual picture of the system and helps to analyse the system in a less inductive manner. Therefore, the purpose of this paper is studying the application of project scheduling in agriculture, for operations scheduling of sugarcane production (preserve operations, harvesting and rationing) using classical GERT method in Khuzestan province of Iran. Results showed that the network model was able to answer any statistic all the questions concerning the project. GERT networks are increasingly becoming a powerful tool for modelling, scheduling, planning, controlling and analysing of agricultural mechanization projects.
\end{abstract}

Keywords: Scheduling, GERT network, Agricultural Mechanization, Sugarcane

\title{
1. Introduction
}

Many different techniques and tools have been developed to support better project planning and these tools are used seriously by a large majority of project managers (Fahimifard \& Kehkha, 2009; Fox \& Spence, 1998; Pollack, 1998). Graphical Evaluation and Review Technique (GERT) is popularly a graphical tool for the analysis of complex systems because GERT can easily analyse stochastic networks with logical node and directed branches (Lin et al, 2011). A GERT network is an activity-on-the-arc network. The network may contain cycles, allowing for the multiple execution of activities during the execution of the project. Each arc (ij) is assigned a weight vector (Pij, Fij). Pij > 0 is the conditional execution probability of the corresponding activity (ij) given that project event $i$ has occurred. Fij is the conditional distribution function of the nonnegative duration dij of activity (ij) given that (ij) is carried out. Pij and Fij are assumed to be independent of the number of times that project event i have occurred or activity (ij) has been executed before, respectively (Neumann, 1999; Neumann, 1990; Neumann, 1984; Neumann \& Steinhardt, 1979). Since the efficiency and capabilities of GERT networks for modelling, simulation, planning, scheduling and analysis of the projects in complicated systems had been proved and confirmed in different fields of industry (Matsumoto et al, 2007; Ahcom 2004; Takanobu et al, 2004; Gauri, 2003; Kenzo \& Nobuyuki, 2002). Also, the planning and project controlling techniques, especially network models, have been used in agricultural projects (Monjezi et al, 2012a; Monjezi et al, 2012b; Abdi et al, 2009). Therefore, the purpose of this paper is studying the application of project scheduling in agriculture, for operations scheduling of sugarcane production (preserve operations, harvesting and rationing) using classical GERT method.

\section{Materials and Methods}

The study was carried out in Khuzestan province of Iran in 2015. Data were collected from variety sources such as reports and statistics of meteorological synoptic stations, opinions and 
comments of Khuzestan Sugarcane and by-Product Research and Training Institute experts and reports and statistics of Sugarcane Agro-Industry. All activity times are given in day. For the sake of completion, a brief introduction of GERT (Manju, \& Pooja, 2007; Cheng, 1994; Whitehouse, 1973) is given. GERT is a procedure, which combines the disciplines of the flow graph theory, Moment Generating Function (MGF) and Project Evaluation and Review Technique (PERT) for analysing stochastic networks having logical nodes and directed branches. Each branch has a probability that the activity associated with it will be performed. Therefore, GERT provides a visual picture of the system by means of the corresponding graph and makes it possible to analyse the given system in a less inductive manner. The results are obtained based on the MGF using Mason's formula, which takes care of all possible products of transmittances of non-intersecting loops described later.

The following steps are employed, when applying GERT:

1. Convert a qualitative description of a system or problem to a model in a stochastic network form.

2. Collect the necessary data to describe the transmittances of the network.

3. Apply Mason's rule to determine the equivalent function or functions of the network.

4. Convert the equivalent function into the following two performance measures of the network:

(a) The probability that a specific node is realized.

(b) The moment generating function of the time associated with a node, if it is realized.

5. Make inferences concerning the system under study from the information obtained in the Step 4.

GERT is based on the following definitions and rules:

- GERT network:

A GERT network generally contains one of the following two types of logical nodes:

(a) Nodes with Exclusive-Or input function and Deterministic output function.

(b) Nodes with Exclusive-Or input function and Probabilistic output function.

Exclusive-Or input: The node is realized; when any arc leading into it is realized. However, one and only one of the arcs can be realized at a given time.

Deterministic output: All arcs emanating from the node are taken, if the node is realized.

Probabilistic output: Exactly one arc emanating from the node is taken, if the node is realized.

In this paper type (b) nodes are used.

- Path:

A path is a series of branches, which joins two nodes and do not pass through any node more 


\section{Macrothink}

Journal of Agricultural Studies

ISSN 2166-0379

2015, Vol. 3, No. 2

than once. The value of a path is the product of the so-called transmittances along the path.

- Loop:

A loop is a series of branches, which emerges from a node, and eventually returns to that node without passing through any node more than once. The value of a loop is equal to the product of the transmittances around the loop. A first order loop can be viewed as a loop having a consecutive path of arrows emerging from a node and returning to the same node. A self-loop can be viewed as a degenerated first order loop.

A Loop of order $\mathrm{n}$ is represented by a set of $\mathrm{n}$ disjoint first order loops.

- Mason's Rule:

In an open flow graph, write down the product of the transmittances along each path from the independent to the dependent variable. Multiply its transmittance by the sum of the non-touching loops to that path. Sum these modified path transmittances and divide by the sum of all the loops in the open flow graph yielding the transmittance T:

$$
T=\frac{\left.\sum \text { (path } \sum \text { nontouching loops }\right)}{\sum \text { loops }}
$$

Where:

$$
\begin{aligned}
& \sum \text { nontouching loops }=1-\sum \text { first order nontouching loops } \\
& +\sum \text { second order nontouching loops } \\
& \quad-\sum \text { third order nontouching loops }+\cdots \\
& \quad \sum \text { loops }=1-\sum \text { first oeder loops }+\sum \text { second order loops }-\cdots
\end{aligned}
$$

W-function for GERT:

In a network $G$ with only GERT nodes, let the random variable $Y_{i j}$ be the duration of the activity $(i, j)$ and $f\left(y_{i j}\right)$ be the conditional probability of the duration $y_{i j}$ of the activity $(i, j)$. The conditional MGF of the random variable $\mathrm{Y}_{\mathrm{ij}}$ is given as:

$$
M_{i j}(s)=E\left[e^{s Y_{i j}}\right]=\sum e^{s Y_{i j}} f\left(Y_{i j}\right)
$$

The conditional probability $p_{i j}$ that the activity $(i, j)$ will be undertaken, given that node $i$ is realized, is multiplied by the MGF to yield a W-function: 


$$
W_{i j}(s)=p_{i j} M_{i j}(s)
$$

The W-function is used to obtain the information about a relationship between the nodes.

\section{Results and Discussion}

GERT network model resulted from sugarcane production (preserve operations, harvesting and rationing) as follows (Fig. 1). Parameters of sugarcane production classical GERT network are presented in Table 1. Due to the nature of the data, the distribution density function of time for each activity, the constant function with zero variance. According to the Materials and Methods, the probability, mean and variance of the completion time of sugarcane production obtained. The worth of different parts of the network is calculated. The relationship 4 shows the worth of equivalent branch that connect the starting node to node 86 .

$$
W_{(t)_{s t a r t-86}}=\left[\left(W_{(t)_{121}} * W_{(t)_{122}}\right)+W_{(t)_{120}}\right] * W_{(t)_{119}}=e^{2 t}\left(0.9 e^{4 t}+0.1\right)
$$

By placing $\mathrm{t}=0$ in function ${ }^{W_{(t)_{s t a r t-86}}}$, probability of Equivalent branch was calculated (according to relationship 5.

$$
P_{\text {start }-86}=W_{(0)_{8 s-86}}=e^{0}\left(0.9 e^{0}+0.1\right)=1
$$

To calculate the mean time from starting node to node 86 , the first derivative of the function $W_{(t)_{s t a r t-86}}$ was taken and the answer was 5.6 days. And by using the relationships 3 and taking second derivative of function ${ }^{W_{(t)_{s t a r t-86}}}$, the variance was obtained 1.44. Also worth of network loops was calculated as follow:

1. The worth of the loop N. 1 with track start-86:

$$
W_{(t)_{L_{11}}}=0.7 * e^{68 t}=0.7 e^{68 t}
$$

2. The worth of the loop N. 2 with track 86-87-88-89-90-start:

$$
W_{(t)_{L_{12}}}=0.1 e^{7 t}\left(0.9 e^{4 t}+0.1\right)
$$




\section{Macrothink}

3. The worth of the loop N. 3 with track 86-91-start:

$W_{(t)_{L_{1 s}}}=0.1 e^{5 t}$

4. The worth of the loop N. 4 with track 86-92-93-94-95-96-97-98-99-100-101-102-103-104105-106-107-108-109-start:

$$
W_{(t)_{L_{14}}}=0.05 e^{41 t} * \frac{e^{t}}{1-0.5 e^{t}}
$$

A prerequisite for completing operation is that each loops in the network be done one time and with significant order (in the case of first loop, Activity No. 123, was repeated 17 times). So the worth of equivalent branch between starting node and node No. 109 was obtained as follows:

$$
\begin{aligned}
& W_{(t)_{\text {start }-109}=} W_{(t)_{\text {start }-86}} * W_{(t)_{L_{11}}} * W_{(t)_{L_{12}}} * W_{(t)_{L_{18}}} * W_{(t)_{L_{14}}} \\
&=e^{2 t}\left(0.9 e^{4 t}+0.1\right) * e^{68 t} * e^{7 t}\left(0.9 e^{4 t}+0.1\right) * e^{5 t} * 0.5 * e^{41 t} \\
& * \frac{e^{t}}{1-0.5 e^{t}}=e^{123 t} *\left(0.9 e^{4 t}+0.1\right)^{2} * \frac{e^{t}}{1-0.5 e^{t}} * 0.5
\end{aligned}
$$

By placing $\mathrm{t}=0$ in the function ${ }^{W_{(t)_{s t a r t-85}}}$, the probability of starting node to node 109 was obtained a hundred percent.

By using Equation 3, the moment generating function $W_{(t)_{s t a r t-86}}$ is:

$$
M_{(t)_{\text {start-109 }}}=e^{123 t} *\left(0.9 e^{4 t}+0.1\right)^{2} * \frac{e^{t}}{1-0.5 e^{t}} * 0.5
$$

Average time between starting node and node N.109, by deriving from the moment generating function ${ }^{W_{(t)_{s t a r t}-86}}$ and placing $\mathrm{t}=0$ was obtained as follows:

$$
\begin{array}{r}
\mu(t)=123 e^{123 t}\left[\left(0.9 e^{4 t}+0.1\right)^{2} * \frac{e^{t}}{1-0.5 e^{t}} * 0.5\right]+\left[7.2 e^{4 t}\left(0.9 e^{4 t}+0.1\right)\right] *\left[e^{123 t}\right. \\
\left.* \frac{e^{t}}{1-0.5 e^{t}} * 0.5\right]+\left[\frac{e^{t}}{\left(1-0.5 e^{t}\right)^{2}} * 0.5\right] *\left[e^{123 t} *\left(0.9 e^{4 t}+0.1\right)^{2}\right]
\end{array}
$$




$$
\mu(0)=132.2=\mu
$$

The second derivative of the moment generating function ${ }^{W_{(t)_{s t a r t} \mathrm{sE}}}$ and placing $\mathrm{t}=0$, the variance between the two nodes was obtained as follows:

$$
\begin{aligned}
\frac{\partial^{2} M_{(\mathrm{t})_{\text {start }-109}}}{\partial \mathrm{t}^{2}}= & {\left[123 * 123 e^{123 t} *\left(0.9 e^{4 t}+0.1\right)^{2} *\left(\frac{e^{t}}{1-0.5 e^{t}} * 0.5\right)\right]+\left[7.2 e^{4 t}\right.} \\
& \left.*\left(0.9 e^{4 t}+0.1\right) * 123 e^{123 t} *\left(\frac{e^{t}}{1-0.5 e^{t}} * 0.5\right)\right]+\left[\frac{e^{t}}{\left(1-0.5 e^{t}\right)^{2}} * 0.5\right. \\
& \left.* 123 e^{123 t} *\left(0.9 e^{4 t}+0.1\right)^{2}\right]+\left[25.92 e^{131 t} *\left(\frac{e^{t}}{1-0.5 e^{t}} * 0.5\right)\right] \\
& +\left[127 e^{127 t} * 7.2\left(0.9 e^{4 t}+0.1\right) *\left(\frac{e^{t}}{1-0.5 e^{t}} * 0.5\right)\right]+\left[\left(\frac{e^{t}}{\left(1-0.5 e^{t}\right)^{2}}\right.\right. \\
& \left.* 0.5) * 7.2 e^{127 t}\left(0.9 e^{4 t}+0.1\right)\right]+\left[\frac{e^{t}\left(1+0.5 e^{t}\right)}{\left(1-0.5 e^{t}\right)^{3}} * 0.5 * e^{123 t}\right. \\
& \left.*\left(0.9 e^{4 t}+0.1\right)^{2}\right]+\left[123 e^{123 t} * \frac{e^{t}}{\left(1-0.5 e^{t}\right)^{2}} * 0.5 *\left(0.9 e^{4 t}+0.1\right)^{2}\right] \\
& +\left[7.2 e^{4 t} *\left(0.9 e^{4 t}+0.1\right) * e^{123 t} * \frac{e^{t}}{\left(1-0.5 e^{t}\right)^{2}} * 0.5\right] \\
& \frac{\partial^{2} M_{(0)} \text { start } 109}{\partial \mathrm{t}^{2}}=17496.12 \\
& \operatorname{Var}_{\text {start }-109}=17496.12-(132.2)^{2}=19.28
\end{aligned}
$$

For each node, to conclude about the probability, mean and variance can use the above procedure and predict various events during operations.so with due attention to certain events that are occurring in the tracks of operation, good decisions can be adopted. 


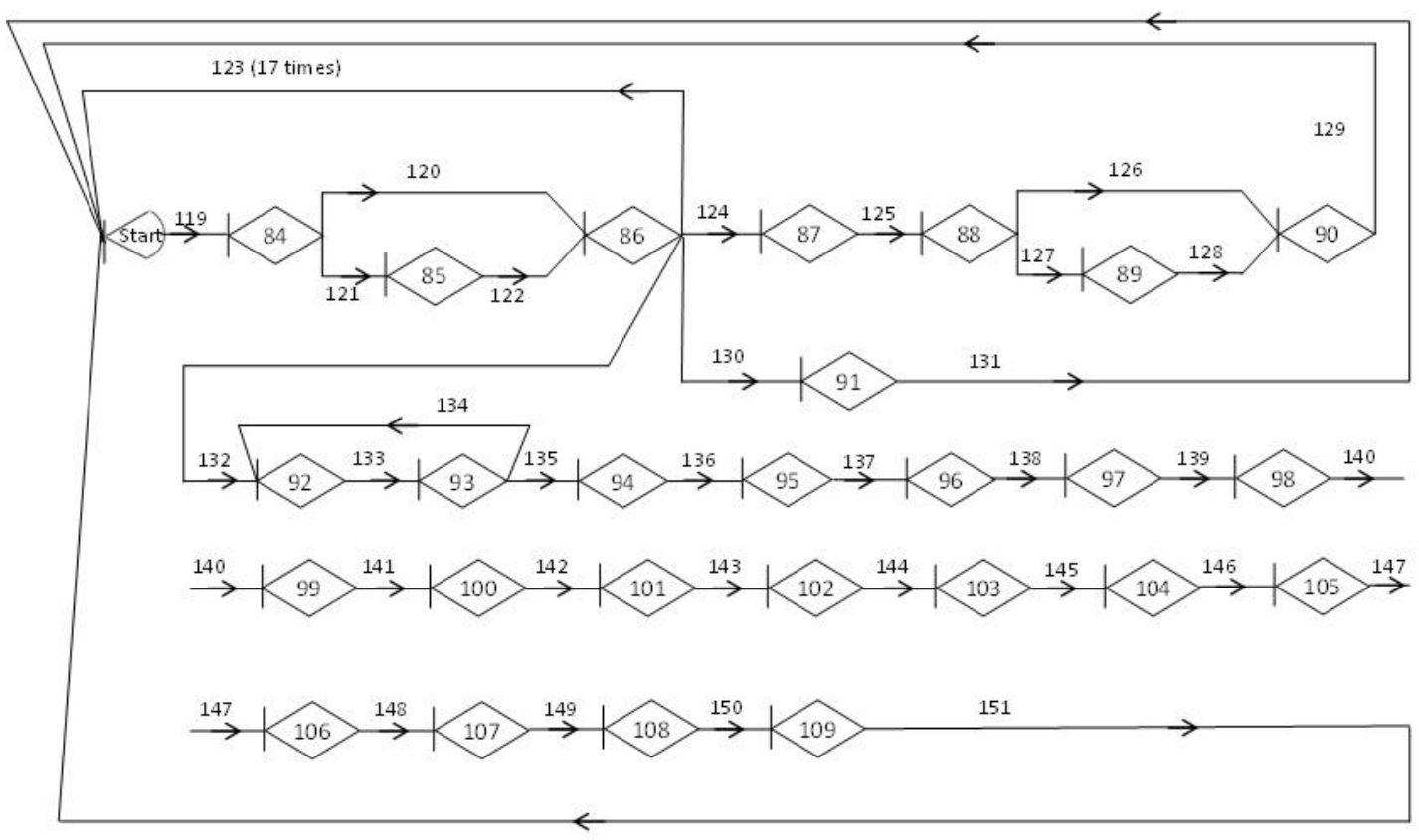

Figure 1. Operations of sugarcane production GERT network

\section{Conclusion}

The purpose of this paper is studying the application of project scheduling in agriculture, for operations scheduling of sugarcane production (preserve operations, harvesting and rationing) using classical GERT method in Khuzestan province of Iran. Results showed that the network model was able to answer any statistic all the questions concerning the project. GERT networks are increasingly becoming a powerful tool for modelling, scheduling, planning, controlling and analysing of agricultural mechanization projects. 


\section{Macrothink}

Table 1. Parameters of sugarcane production classical GERT network

\begin{tabular}{|c|c|c|c|c|c|c|}
\hline $\begin{array}{l}\text { Activity } \\
\text { code }\end{array}$ & Activity description & $\begin{array}{c}\text { Activity } \\
\text { time }\end{array}$ & $\begin{array}{c}\text { Repetition } \\
\text { (times) }\end{array}$ & $\begin{array}{l}\text { Moment Generating } \\
\text { Function } \\
\mathbf{M}_{1 \mathrm{j}}(\mathbf{t})\end{array}$ & $\begin{array}{c}\text { Probability } \\
\mathbf{P}_{\mathrm{ij}}\end{array}$ & $\begin{array}{l}\text { Worth of } \\
\text { activity } \\
\mathbf{W}_{\mathrm{ij}}(\mathrm{t})\end{array}$ \\
\hline 119 & Sampling and determination of crop water requirement & 2 & 1 & $\operatorname{Exp}(2 \mathrm{t})$ & 1 & $\operatorname{Exp}(2 \mathrm{t})$ \\
\hline 120 & Decide to non- irrigation & 0 & 1 & 1 & 0.1 & 0.1 \\
\hline 121 & Decide to irrigation & 0 & 1 & 1 & 0.9 & 0.9 \\
\hline 122 & Irrigation & 4 & 1 & $\operatorname{Exp}(4 t)$ & 1 & $\operatorname{Exp}(4 t)$ \\
\hline 123 & Irrigation (The number of repeat 17 times) & 4 & 17 & $\operatorname{Exp}(68 t)$ & 0.7 & $0.7^{\mathrm{X}} \operatorname{Exp}(68 \mathrm{t})$ \\
\hline 124 & Biological pest control- parasitoid wasps (second stage) & 1 & 1 & $\operatorname{Exp}(1 \mathrm{t})$ & 0.1 & $0.1^{\mathrm{X}} \operatorname{Exp}(1 \mathrm{t})$ \\
\hline 125 & Sampling and determination of crop fertilizer requirement & 2 & 1 & $\operatorname{Exp}(2 \mathrm{t})$ & 1 & $\operatorname{Exp}(2 t)$ \\
\hline 126 & Decide to non- top dressing & 0 & 1 & 1 & 0.1 & 0.1 \\
\hline 127 & Decide to top-dressing & 0 & 1 & 1 & 0.9 & 0.9 \\
\hline 128 & Irrigation and top-dressing & 4 & 1 & $\operatorname{Exp}(4 t)$ & 1 & $\operatorname{Exp}(4 t)$ \\
\hline 129 & Irrigation & 4 & 1 & $\operatorname{Exp}(4 \mathrm{t})$ & 1 & $\operatorname{Exp}(4 t)$ \\
\hline 130 & Biological pest control- parasitoid wasps (third stage) & 1 & 1 & $\operatorname{Exp}(1 \mathrm{t})$ & 0.1 & $0.1^{\mathrm{X}} \operatorname{Exp}(1 \mathrm{t})$ \\
\hline 131 & Irrigation & 4 & 1 & $\operatorname{Exp}(4 t)$ & 1 & $\operatorname{Exp}(4 t)$ \\
\hline 132 & Biological pest control- parasitoid wasps (fourth stage) & 1 & 1 & $\operatorname{Exp}(1 \mathrm{t})$ & 0.1 & $0.1^{\mathrm{x}} \operatorname{Exp}(1 \mathrm{t})$ \\
\hline 133 & Sugarcane sap test determine the time of harvesting & 1 & 1 & $\operatorname{Exp}(1 \mathrm{t})$ & 1 & $\operatorname{Exp}(1 \mathrm{t})$ \\
\hline 134 & Diagnosis of product prematurity & 0 & 1 & 1 & 0.5 & 0.5 \\
\hline 135 & Diagnosis of product ripe & 0 & 1 & 1 & 0.5 & 0.5 \\
\hline 136 & Cut off irrigation and collecting pipes & 1 & 1 & $\operatorname{Exp}(1 \mathrm{t})$ & 1 & $\operatorname{Exp}(1 \mathrm{t})$ \\
\hline
\end{tabular}




\begin{tabular}{|c|c|c|c|c|c|c|}
\hline $\begin{array}{l}\text { Activity } \\
\text { code }\end{array}$ & Activity description & $\begin{array}{l}\text { Activity } \\
\text { time }\end{array}$ & $\begin{array}{c}\text { Repetition } \\
\text { (times) }\end{array}$ & $\begin{array}{c}\text { Moment Generating } \\
\text { Function } \\
\mathbf{M}_{\mathrm{ij}}(\mathbf{t})\end{array}$ & $\begin{array}{c}\text { Probability } \\
\mathbf{P}_{\mathbf{i j}}\end{array}$ & $\begin{array}{l}\text { Worth of } \\
\text { activity } \\
\mathbf{W}_{\mathrm{ij}}(\mathrm{t})\end{array}$ \\
\hline 137 & $\begin{array}{c}\text { Leveling of marginal lands and filling the beginning of } \\
\text { furrows }\end{array}$ & 1 & 1 & $\operatorname{Exp}(1 t)$ & 1 & $\operatorname{Exp}(1 t)$ \\
\hline 138 & The spunk supply and fire field & 1 & 1 & $\operatorname{Exp}(1 \mathrm{t})$ & 1 & $\operatorname{Exp}(1 \mathrm{t})$ \\
\hline 139 & Harvester, tractor and transporter supply & 2 & 1 & $\operatorname{Exp}(2 t)$ & 1 & $\operatorname{Exp}(2 t)$ \\
\hline 140 & Oil and fuel for harvesting & 1 & 1 & $\operatorname{Exp}(1 \mathrm{t})$ & 1 & $\operatorname{Exp}(1 \mathrm{t})$ \\
\hline 141 & Harvesting and carrying cane to the factory & 8 & 1 & $\operatorname{Exp}(8 t)$ & 1 & $\operatorname{Exp}(8 t)$ \\
\hline 142 & Tractor, trailer and grap loader supply & 2 & 1 & $\operatorname{Exp}(2 t)$ & 1 & $\operatorname{Exp}(2 t)$ \\
\hline 143 & Liliko & 2 & 1 & $\operatorname{Exp}(2 t)$ & 1 & $\operatorname{Exp}(2 t)$ \\
\hline 144 & Oil and fuel for ratooning & 1 & 1 & $\operatorname{Exp}(1 \mathrm{t})$ & 1 & $\operatorname{Exp}(1 t)$ \\
\hline 145 & Subsoiling & 5 & 1 & $\operatorname{Exp}(5 t)$ & 1 & $\operatorname{Exp}(5 t)$ \\
\hline 146 & Reshaper supply & 1 & 1 & $\operatorname{Exp}(1 \mathrm{t})$ & 1 & $\operatorname{Exp}(1 \mathrm{t})$ \\
\hline 147 & Ratoon and reshape & 4 & 1 & $\operatorname{Exp}(4 t)$ & 1 & $\operatorname{Exp}(4 t)$ \\
\hline 148 & Ratoon fertilizering & 4 & 1 & $\operatorname{Exp}(4 t)$ & 1 & $\operatorname{Exp}(4 t)$ \\
\hline 149 & Ratoon spray & 2 & 1 & $\operatorname{Exp}(2 t)$ & 1 & $\operatorname{Exp}(2 t)$ \\
\hline 150 & Piping for irrigation & 1 & 1 & $\operatorname{Exp}(1 \mathrm{t})$ & 1 & $\operatorname{Exp}(1 \mathrm{t})$ \\
\hline 151 & Primary irrigation & 4 & 1 & $\operatorname{Exp}(4 t)$ & 1 & $\operatorname{Exp}(4 t)$ \\
\hline
\end{tabular}




\section{References}

Abdi, R., Ghasemzadeh, H. R., Abdollahpur, S., Sabzehparvar, M. \& MohammadiNasab, A. D. (2009). Modeling and resource allocation of agricultural mechanization projects with GERT networks. Journal Food, Agricultural \& Environment, 7, 438-441.

Ahcom J. (2004). A model for benchmarking contractors project management elements in Saudi Arabia. Ph.D. Thesis. King Fahd University of Petroleum and Minerals.

Cheng, C. H. (1994). Fuzzy consecutive-k-out-of-n:F system reliability. Microelectron. Reliability. 34, 1909-1922. http://dx.doi.org/10.1016/0026-2714(94)90286-0

Fahimifard, S. M., \& Kehkha, A. A. (2009). Application of project scheduling in agriculture (case study: grape garden stabilization). American-Eurasian Journal of Agricultural and Environmental Science, 5(3), 313-321

Fox, T. L., \&. Spence, J. W. (1998). Tools of the trade: A survey of project management tools. Project Management Journal, 29, 20-28

Gauri, S. (2003). GERT analysis of sampling plan for system reliability. Department of Mathematics and Statistics, Ravishankar University, Raipur (M.P.), India. Microelectronics and Reliability, 23-25

Kenzo, K., \& Nobuyuki, N. (2002). Efficient Monte Carlo simulation method of GERT-type network for project management. Computer and Industrial Engineering, 42, 521-531. http://dx.doi.org/10.1016/S0360-8352(02)00050-5

Lin, K. P., Wena, W. U., Chou, C. C., Jen, C. H., \& Hung, K. C. (2011). Applying fuzzy GERT with approximate fuzzy arithmetic based on the weakest t-norm operations to evaluate repairable reliability, Applied Mathematical Modelling, 35, 5314-5325. http://dx.doi.org/10.1016/j.apm.2011.04.022

Manju, A., \& Pooja, M. (2007). GERT Analysis of m-consecutive-k-out-of-n:F Systems with Dependence, Economic Quality Control, 22(1), 141-157

Matsumoto, T., Tokimatsu, K., Kosugi, T., \& Yoshida, H. (2007). Evaluation for development of superconducting technologies in power sectors using GERT. Acta Press, USA. Power and energy systems.

Monjezi, N.; Sheikhdavoodi, M. J., \& Basirzadeh, H. (2012a). Application of Project Scheduling in Agriculture (Case Study: Mechanized Greenhouses Construction Project). Research Journal of Applied Sciences, Engineering and Technology, 4(3), 241-244

Monjezi, N.; Sheikhdavoodi, M. J.; Basirzadeh, H. \& Zakidizaji, H. (2012b). Analysis and Evaluation of Mechanized Greenhouse Construction Project using CPM Methods. Research Journal of Applied Sciences, Engineering and Technology, 4(18), 3267-3273

Neumann, K. (1999). Scheduling of Projects with Stochastic Evolution Structure, Chapter 14 in Weglarz, J. (ed.), Project Scheduling - Recent Models, Algorithms and Applications, Kluwer Academic publishers, 309-332. 
http://dx.doi.org/10.1007/978-1-4615-5533-9_14

Neumann, K., (1990). Stochastic Project Networks, Lecture Notes in Economics and Mathematical Systems, Springer, Berlin, 344. http://dx.doi.org/10.1007/978-3-642-61515-3

Neumann, K. (1984). Recent Developments in Stochastic Activity Networks, Information, 22(3), 219-248

Neumann, K., \& Steinhardt, U. (1979). GERT Networks and the Time-Oriented Evaluation Projects, Lecture Notes in Economics and Mathematical Systems, Springer, Berlin, 172. http://dx.doi.org/10.1007/978-3-642-95363-7_5

Pollack, J. B. (1998). Project management software usage patterns and suggested research directions for future development. Project Management Journal, 29, 19-29.

Takanobu, K., Ayami, H., \& Tsuyoshi, M. (2004). Time to realization: Evaluation of CO2 capture technology R \& D by GERT analyses. Energy, 29, 1297-1308. http://dx.doi.org/10.1016/j.energy.2004.03.088

Whitehouse, G. E. (1973). Systems Analysis and Design Using Network Techniques. Prentice-Hall, Englewood Cliffs, New Jersey

\section{Copyright Disclaimer}

Copyright for this article is retained by the author(s), with first publication rights granted to the journal.

This is an open-access article distributed under the terms and conditions of the Creative Commons Attribution license (http://creativecommons.org/licenses/by/3.0/). 